\title{
Design an Occlusion Calibrator using XGZP6887 and Servo Motor MG966R as a Simulator
}

\author{
Rizki Auliya\#, Syaifudin, Liliek Soetjiatie \\ Department of Medical Electronics Engineering Technology Poltekkes Kemenkes, Surabaya \\ Jl. Pucang Jajar Timur No. 10, Surabaya, 60245, Indonesia \\ Corresponding Author: Liliek Soetjiatie (email: lilik06@poltekkesdepkes-sby.ac.id)
}

\begin{abstract}
Article Info
Article History:

Received Jan 5, 2021

Revised Feb 19, 2021

Accepted Feb 21, 2021

\section{Keywords:}

Infusion Pump

Occlusion

Pressure

XGZp6887Servo motor

Abstract

A foreign fluid that enters the patient can cause some bodily reactions including infection, air embolism and blood clot. Side effects given will be fatal to the body, one of which occurs the blockage of the capillary vessels in the heart that can cause heart attack to stroke. The purpose of this research is to design a tool that can be used to measure maximum pressure as a form of the calibration of the syringe pump and infusion pump. The contribution of this research is that the system can simulate the presence of blockages in fluid flow and detect large pressure values detected by the Under Test Unit (UUT) with a motor peer round system that opens/closes fluid flow. Servo Motor MG966R simulate the presence of blockage with constant motor degree until the alarm UUT reads, then Sensor XGZP6887 detects the pressure generated by the blockage and processed by the microcontroller and displayed on the LCD display of the character. This study resulted in a maximum pressure average value of 7.12 Psi. The results showed that data retrieval had an error value of $\mathbf{- 0 . 1 2}$. This research can be implemented to perform pressure measurements on the syringe pump or infusion pump.
\end{abstract}

\author{
Corresponding Author: \\ nyong74@yahoo.com \\ Department of Medical Electronics Engineering Technology \\ Poltekkes Kemenkes, Surabaya
}

This work is an open accessarticle and license dunder a Creative Commons Attribution-Share Alike 4.0 International License(CC BY-SA 4.0).

\section{INTRODUCTION}

The medical world of intravenous fluid administration in patients has a major effect on the recovery of patient during treatment. Intravenous fluid inserted in the patient is medicines and fluids that can overcome the effects of dehydration patients suffer. Intravenous fluid inserted into the patient's body using injection.[1] In addition, this fluid can also be inserted into the blood vessels using the principle of gravity applied to the infusion fluid. In practice, currently to instill pharmaceutical substances and drugs no longer requires oversight and has been based on preliminary clinical studies that set the prescription rules required by the patient.[2]Intravenous fluid can be inserted into the blood vessels automatically using a tool namely infusion pump and syringe pump. Fluid intake into the human body is certainly not separated from the various problems associated with blood vessels that can affect the performance of various organs in the human body including the heart and lungs. The presence of foreign fluid that enters the patient can cause some bodily reactions, such as infection, air embolism and blood clot. Side effects given will be fatal to the body, one of which occurs the blockage of the capillary vessels in the heart that can cause heart attack to stroke. When the hose has an occlusion, the prescribed medicines and nutrients cannot enter the patient's body. [3] Therefore, there is an early detection of the tools to be used to incorporate intravenous fluids into the body. Infusion pump or syringe pump tool as a medium that helps the importation of fluid should be able to detect any errors to minimize the side effects of excessive one of them blockage or embolism air with the maximum limit of pressure allowed to enter the patient's body. Signs of obstruction is the occurrence of Phlebitis in patients. Phlebitis is an inflammation of the vein veins that occur due to damage to the venous walls causing the release of inflammatory mediators and clot formation. [4] External factors that cause it are needle size, infuse fluid type, the location of the stabilizing infuse, intravenous treatment (infuse), the length of intravenous installation (infuse) and the infuse installation technique. [5] Therefore, It is important to calibrate the pressure that will be 
detected by the syringe pump or infusion pump. In Addition to the internal factors of the patient's body, the use of tools in the long term can also cause an accuracy change in measurement, so it is important to do a method of calibration. Medical devices are periodically required to calibrate at least once a year. [6] Based on Permenkes no 54 year 2015, the syringe pump and infusion pump are part of several medical equipment that must be calibrated. Tool that can be used to calibrate the syringe pump and infusion pump infusion pump Analyzer that can detect flow rate and occlusion in both tools.

Similar Research has been conducted by several researchers, namely: Thongpance, et al (2012) with the method of reading sensors to the occlusion of the syringe pump without the occlusion simulator [7] and updating its research (2014) with the same method but having a smaller error value[3]; Peng Zhang (2009) with pressure sensor reading method and occlusion simulator using three-way tap with $\pm 1 \%$ accuracy[8]; Yamamoto, et al (1990) with the method of using load cell to detect any pressure on the vein[9]; and Kendre Saraswati Vasantrao (2017) with the Generic G1/4 sensor as the pressure sensor to detect pressure when there is leakage in the pipeline[10]. Of the five, the research still has several shortcomings, namely the occlusion method of measurement is still using conventional methods and yet provide precision and precise measurements.

Based on the weaknesses and limitations mentioned earlier researchers, among others: 1) methods used have not achieved accuracy, 2) displayed pressure values are not precise, 3) the use of conventional occlusion simulation, the purpose of this research is to calibrate the infusion pump and syringe pump by displaying the occlusion measurement using the pressure simulation method by the servo motor.

The article is composed of chapter II of the Literature Review, chapter III contains the research methodology, chapter IV contains the results of measurement and analysis, chapter V contains the discussion, chapter VI contains the conclusion and the bibliography.

\section{MATERIALS AND METHODS}

\section{A. Experimental Setup}

This study uses the TOP 5300 syringe pump as a measurement subject and data collection was repeated 6 times.

\section{B. Materials and Device}

This study uses the XGZP6887 [11] (CFSensor, China) sensor to measure pressure value (Psi). Driver solenoid circuit to ON/OFF solenoid valve. IC ATMEGA Microcontroller 328 was used to process the data read by the sensor XGZP6887. The LCD character $20 \times 4$ as the display shows the readable pressure value, time counter and the highest-pressure value. Servo motors MG966R as flow clogging simulators and UBEC as DC regulators for servo motors. Using a 5VDC power supply for the supply of XGZP6887 sensor voltage and 3 batteries for servo motor voltage supply.

\section{Experiment}

In this study, the researchers simulate the pressure on the syringe pump fluid using a servo motor and measure the highest pressure measured when the alarm is active.

\section{The Diagram Block}

When the power button is activated, the whole series will get a supply voltage. Before the measurement process is carried out, activate the syringe pump which will be calibrated with a flow rate setting of $100 \mathrm{ml} / \mathrm{h}$. Set the pressure limit required on the calibration tool and press start. Servo motors will suppress liquid flow and cause occlusion. The measurement results will be displayed on the LCD character (Fig. 1).

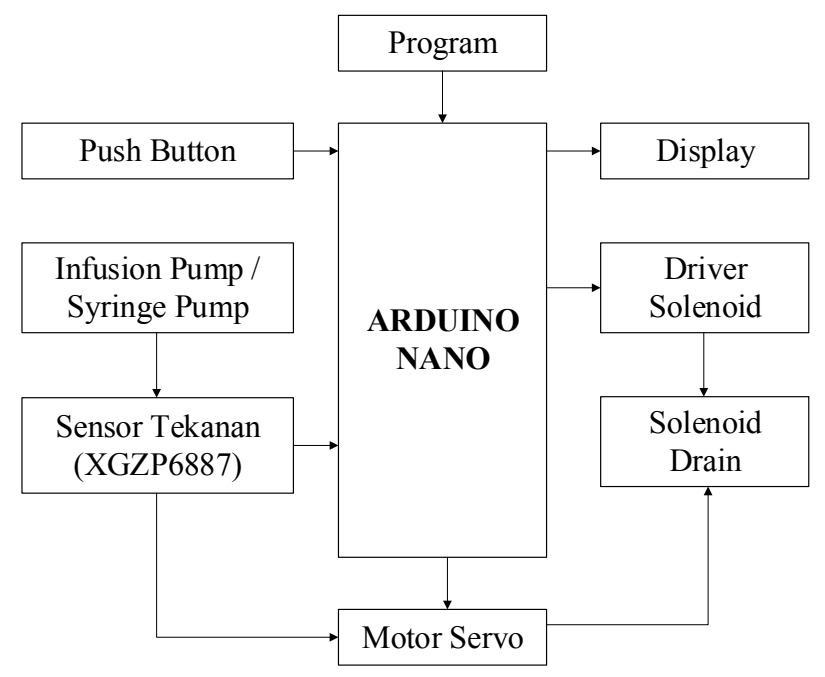

Fig 1. The diagram block of the Infusion Device Analyzer

\section{E. The Flowchart}

By the time the power button is pressed then all the circuit will have voltage including sensor, if the sensor has been getting a voltage means the sensor is in a state ready or standby. The flowchart of the proposed method is showed in Fig. 2. Activate the syringe pump which will be calibrated with a flow rate setting of $100 \mathrm{ml} / \mathrm{h}$, and press start. After that the sensor will start working and servo motors suppress liquid flow then data will be processed by ATMEGA328 (Fig. 3). The alarm on the active syringe pump will display calibration data on the LCD character. Press stops to display the calibration results and complete the calibration process.

\section{F. Circuit}

\section{1) Pin Out of microcontroller}

The Arduino board hardware consist of many components that combine to make it work. [12] Pin out on ATMEGA328 can be used for output and input pins in digital or analog data processing. Data processing can be in the form 
of ADC (Analog-to-Digital Converter) or DAC (Digital-toAnalog Converter).

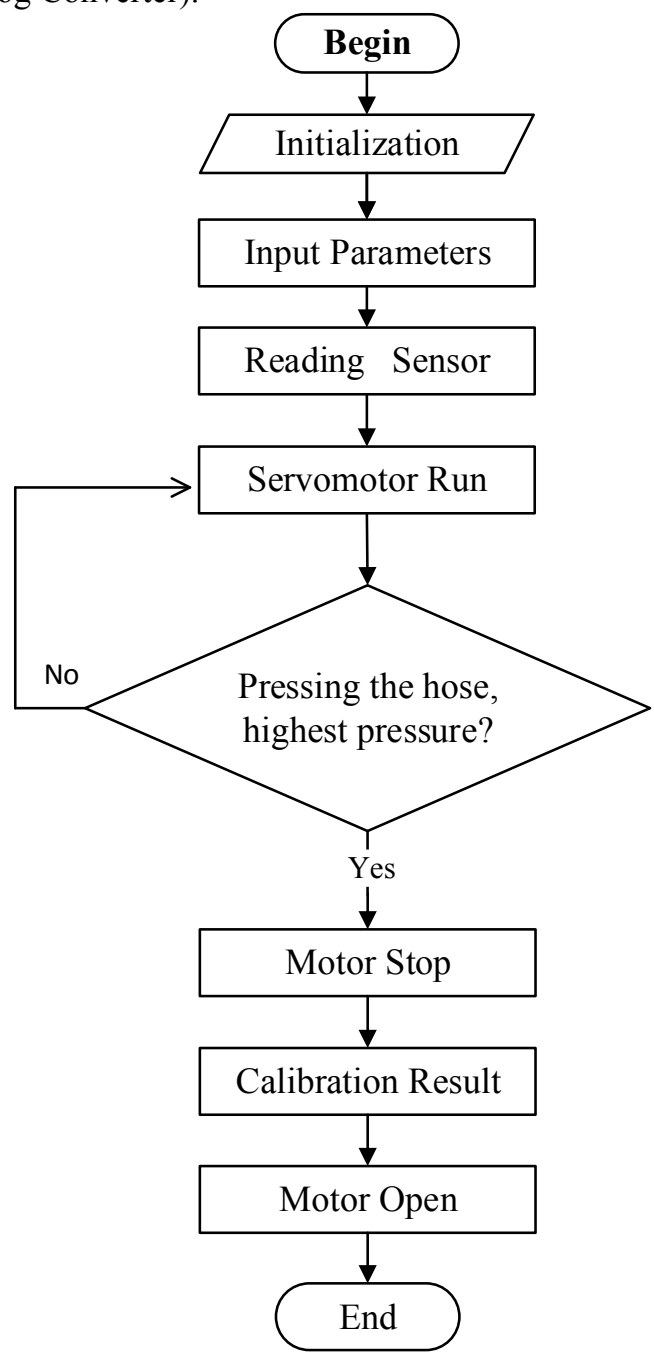

Fig 2. The Flowchart of the Arduino Program

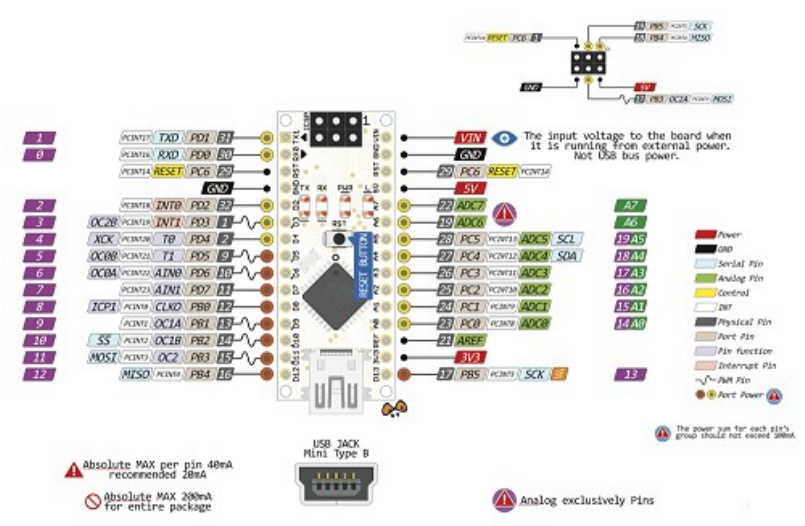

Fig 3. Pin out of microcontroller

\section{2) Sensor Circuit}

The XGZP6887 sensor has a analog value output (Fig. 4). The value released is the ADC value that has been processed by the XGZP6887 Sensor itself which is then processed by the microcontroller.

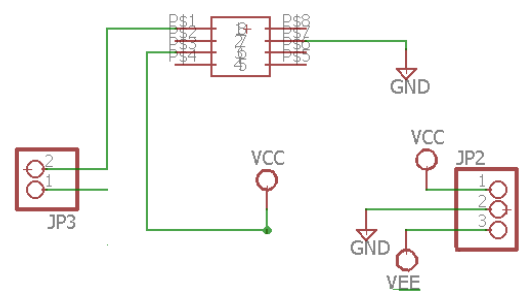

Fig 4. Sensor Circuit

\section{3) Solenoid Driver Circuit}

Solenoid valve works to remove the measured fluid. Solenoid valve is controlled by a microcontroller through a series of solenoid drivers. Solenoid driver functions to regulate $12 \mathrm{VDC}$ voltage to activate the solenoid valve.

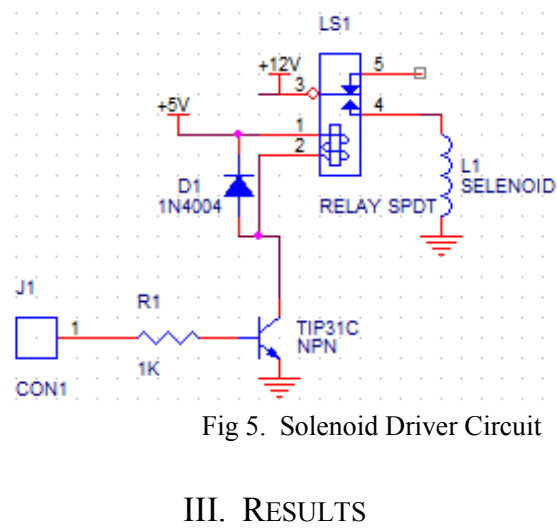

In this study, measurements were made on TOP5300 as a Unit Under Test (UUT). The results (Fig. 6 and Fig.7) show as the results of the circuit used to run the system and detect water pressure values.

A. Results of sensor circuit design

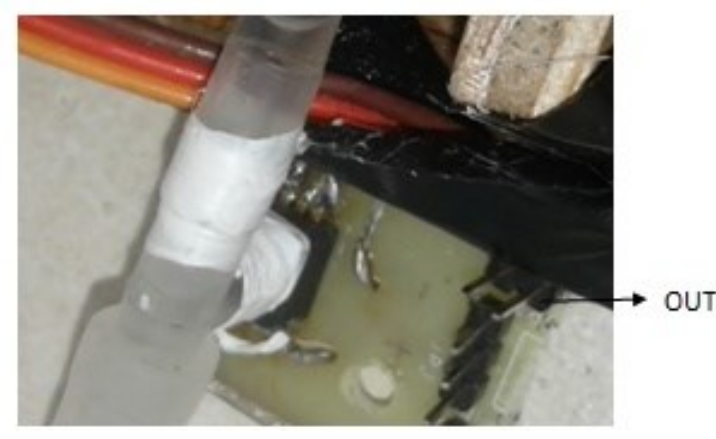

Fig 6. Results of sensor circuit design 


\section{B. Result of Solenoid driver circuit design}

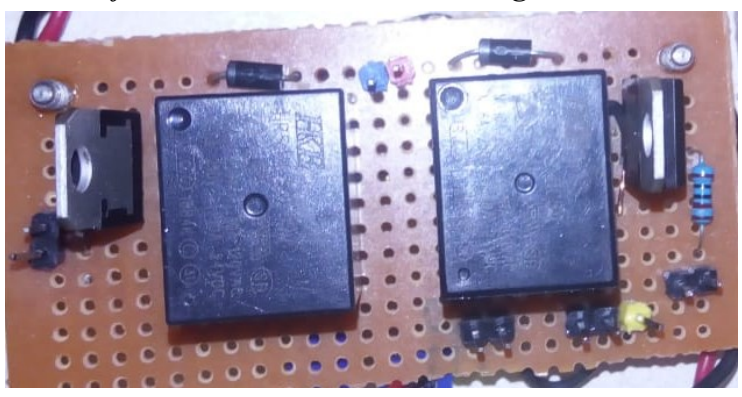

Fig 7. Result of Solenoid driver circuit design

C. Listing program for pressure sensor readings

void occ ()\{
int val $=$ analogRead (sensor); // sensor reading
float input $=((($ val/2.92285713)/6.89476)-2.1); // pressure
formula
if(input $>=30)\{$
input $=0 ;\}$
Serial.println (val);
lcd.setCursor $(12,2) ;$
lcd.print (input,1);
if( ref $<=$ input $)\{$
ref= input; $\}$
else \{
ref=ref; $\}$
lcd.setCursor $(12,3) ;$
lcd.print (ref);
delay $(500) ;$

The data above functions as a sensor reading in the form of analog data that is converted into digital data, then the data is converted to the amount of Psi to display on the LCD. the displayed pressure will be compared with the current psi, the highest-pressure value will be displayed at peak psi as a result of calibration.

D. Listing program to regulate the movement of servo motors

void motor() \{

switch (kec) \{

case 0: motorServo.write(0); //Serial.println ("derajat 0"); delay (1000); break;

case 1: motorServo.write(15); //Serial.println ("derajat 15"); delay (1000); break;

case 2: motorServo.write(30); //Serial.println ("derajat 30"); delay (1000); break;

case 3: motorServo.write(45); //Serial.println ("derajat 45"); delay (1000); break;

case 4: motorServo.write(60); //Serial.println ("derajat 60"); delay (1000); break;

case 5: motorServo.write(75); //Serial.println ("derajat 75"); delay (1000); break;

case 6: motorServo.write(90); //Serial.println ("derajat 90"); delay (1000); break;

default: motorServo.write $(0)$;

\section{\} \}}

The above program functions as a regulator of the running of the motor using a degree angle so that it is constant at a certain time.

\section{E. Program initialization}

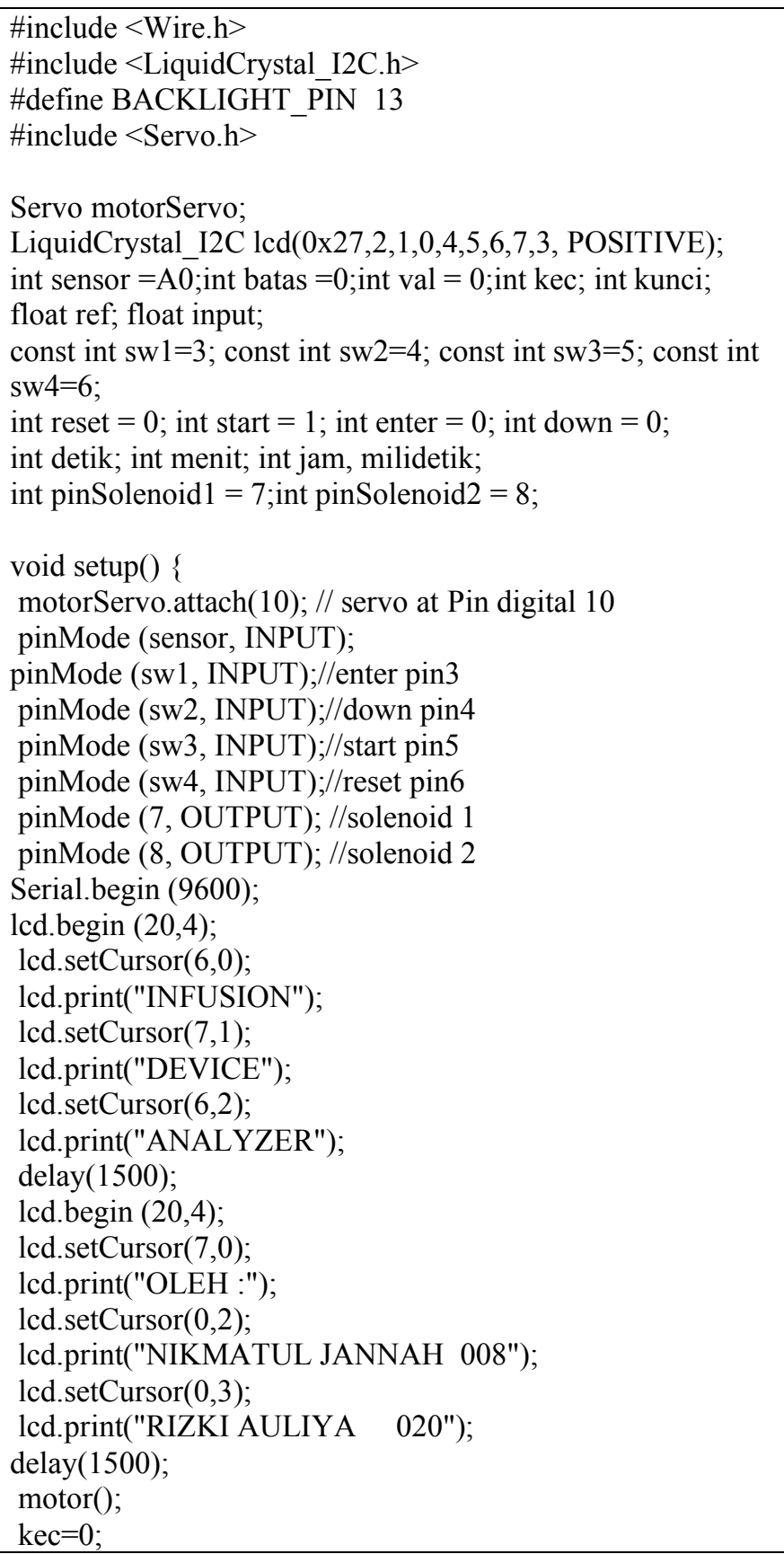


lcd.clear();

The above program is for initializing LCD character 20x4, Servo Motor MG966R, XGZP6887 sensor (Fig. 6) and Solenoid Driver (Fig. 7). In addition, this program is for initial display on LCD characters.

\section{F. Listing program for Display Functions}

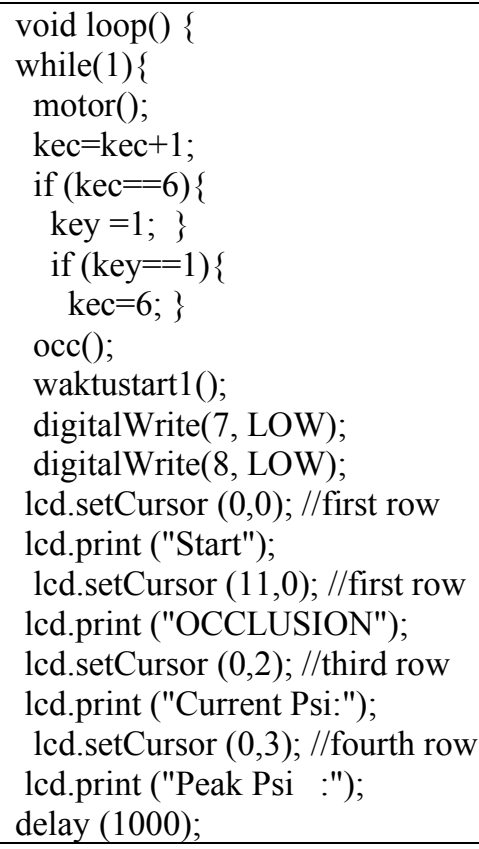

The above program is an order to display data or values that have been processed by the previous program and then communicated with the LCD TFT that is the pressure value data (Psi). TABLE I shows the measurement results 6 times on the TOP5300 Syringe Pump.

\section{$G$. The results of measurements of pressure values at TOP5300}

TABLE I. THE RESULTS OF MEASUREMENTS OF PRESSURE VALUES AT TOP5300

\begin{tabular}{cccccccc}
\hline \multirow{2}{*}{ No. } & \multirow{2}{*}{ Flow rate } & \multicolumn{6}{c}{ Measurement Results (Psi) } \\
\cline { 3 - 7 } & & $\mathrm{X} 1$ & $\mathrm{X} 2$ & $\mathrm{X} 3$ & $\mathrm{X} 4$ & $\mathrm{X} 5$ & X6 \\
\hline 1. & $100 \mathrm{~mL} / \mathrm{h}$ & 6.75 & 7.54 & 7.41 & 7.59 & 6.48 & 6.95 \\
\hline
\end{tabular}

TABLE 1 above shows the measurement results of the tools on TOP5300 as Unit Under Test (UUT).

\section{DISCUSSION}

In this study, researchers used TOP5300 as UUT with 6 times data collection. The results obtained from this measurement are an average maximum value of 7.12 Psi. From the results of these measurements, it can be seen that the TOP5300 meets the ECRI 416-0595 standard. This is the development of a method that is better than previous research with a focus of research only on water pressure detection. [3], [7]-[10] The use of this method can produce significant pressure values for further testing. However, this study does not refer to standard comparison tools, so it cannot be applied to actual calibration. This tool can only be implemented for further research in the use of similar methods.

\section{CONCLUSION}

The purpose of this study is to determine the suitable method for calibration of occlusion in the syringe pump or infusion pump. This study has found that a possible method suitable for simulating the blockage and measuring the pressure value is to use the XGZP6887 water pressure sensor and servo motor. In short, this research reveals the following: the method of simulating blockages in liquids and measuring pressure values is part of the occlusion calibration process in infusion device analyzers. Further experimental investigations are needed to estimate the correct value of the pressure detected by the water pressure sensor.

\section{REFERENCES}

[1] S. Pintasari, "Rancang Bangun Infusion Pump Analyzer." 2019.

[2] U. States, “(12) Patent Application Publication (10) Pub. No.: US 2012/0016295 A1," vol. 1, no. 19, 2012.

[3] N. Thongpance and K. Roongprasert, "Design and construction of Infusion Device Analyzer," 2014.

[4] S. D. Richard, "Pemberian Obat Melalui Intravena terhadap Kejadian Phlebitis pada Pasien Rawat Inap di Rumah Sakit," J. STIKES Vol. 6, No. 1, Juli 2013, vol. 6, no. 1, pp. 63-73, 2013.

[5] S. Fotriyanti, "Faktor Yang Mempengaruhi Terjadinya Phlebitis di Rumaah Sakit Bhayangkara TK II. H.S. Samsoeri Mertojoso Surabaya," J. Berk. Epidemiol., vol. 3, no. 2, pp. 217-229, 2015.

[6] Menteri Kesehatan Republik Indonesia, Permenkes 2015, vol. 53, no. 5. 2015.

[7] N. Thongpance, Y. Pititeeraphab, and M. Ophasphanichayakul, "The Design and Construction of Infusion Pump Calibrator," vol. 100, pp. 35, 2012.

[8] P. Zhang, S. Wang, C. Yu, and M. Zhang, "Design of occlusion pressure testing system for infusion pump," vol. 2, no. 6, pp. 431-434, 2009.

[9] A. Yamamoto, Yoshitake; Yamamoto, Tatsuma; Oberg, P. Ake; Yoshida, "Venous Occlusion Plethysmography Using a Load Cell as the Sensing Element," vol. 39, no. December, pp. 987-990, 1990.

[10] K. S. Vasantrao, "WSN Based water pipeline leakage detection," 2017 Int. Conf. Comput. Commun. Control Autom., pp. 1-5, 2017.

[11] P. Accuracy et al., "XGZP6887A Pressure Sensor Module."

[12] Y. A. Badamasi, "The working principle of an Arduino," Proc. 11th Int. Conf. Electron. Comput. Comput. ICECCO 2014, 2014. 